\title{
THE RELATIONSHIP BETWEEN USING INSULIN AND SUFFERING ALZHEIMER'S DISEASE IN PATIENTS WITH DIABETES: A TWO- YEAR STUDY
}

\author{
Zeinab Raisifar ${ }^{1}$, Alieh Afshar Nia ${ }^{1}$, Mostafa Madmoli*2, Yaghoob Madmoli ${ }^{1}$ \\ ${ }^{1}$ MSc Student of Nursing, Student Research Committee, Ahvaz Jundishapur University of Medical Sciences, \\ Ahvaz, Iran; \\ ${ }^{2 *}$ Emergency Medical Technician, Dezful University of Medical Sciences, Dezful, Iran; \\ "Corresponding author Mostafa Madmoli, email: mostafamadmoli10@yahoo.com;
}

Received May, 2018; Accepted May, 2018; Published June, 2018;

DOI: https://doi.org/10.31407/ijees8324

UOI license: http://u-o-i.org/1.01/ijees/31112323

\begin{abstract}
Introduction: with increase in age and reaching old age, the incidence of some physical and mental disorders is something expected. Progressive loss of cognitive function, usually happening at old age, is known as dementia. Thus, the purpose of this study was to determine the relationship between using insulin and Alzheimer's disease in patients with diabetes: a two-year study. Materials and methods: In this retrospective descriptive-analytical study, all patients admitted to Khatam-al-Anbia Hospital in Shoushtar during 2015-2016 entered the study. The data needed for the study was extracted by studying and reviewing the patients' files during the mentioned years in Khatam-al-Anbia Hospital's archives. In this study, the files of 19995 patients admitted to Khatam-al-Anbia Hospital in Shoushtar were studied. Data were entered into SPSS 16 and analyzed. Results: concerning the relationship between diabetes and Alzheimer's disease, the results showed that 42 (3.3\%) patients had Alzheimer's disease, whereas 1214 (96.6\%) of the patients had no Alzheimer's disease, and no significant relationship was observed between diabetes and Alzheimer's diseases and significant relationship between insulin and suffering Alzheimer's disease( $p<.002)$. Conclusion: In the present study, significant relationship was found between insulin and suffering Alzheimer's disease. This study also showed that It is possible that diabetic patients will not get Alzheimer's without using insulin, but diabetic patients with a history of more than two years of age with using insulin, may that Suffered to an insulin resistance and And then Alzheimer's higher prevalence due to inappropriate use of the drug without prescription. Of course, it is necessary to carry out more extensive research in this field to find out the relation between these two diseases. For this reason, it is suggested that more extensive studies be carried out on patients with diabetes and Alzheimer's patients. For this reason, studies with a larger sample size are required.
\end{abstract}

Keywords: Alzheimer's disease, diabetes, using insulin, insulin resistance 